\title{
Kitcher and Frege on A Priori Knowledge
}

\author{
Christoph C. Pfisterer
}

\begin{abstract}
Summary: In his book The Nature of Mathematical Knowledge and in a series of articles, Philip Kitcher attacks the traditional conception of a priori mathematical knowledge. The reliabilism he develops as an alternative situates all our knowledge within a psychological framework. However, in Frege's Epistemology he claims that Frege's conception of a priori knowledge is compatible with a psychological account. Kitcher attributes to Frege a traditional concept of proof, according to which mathematical and logical proofs are psychological activities. I shall argue that Kitcher's interpretation conflicts with Frege's anti-psychologistic injunction against confusing reasons with causes. Moreover, the psychological explanation obscures one of the most interesting features of a priori knowledge.
\end{abstract}

\section{Kitcher's definition of a priori knowledge}

At first glance, Frege's and Kitcher's notions of a priori knowledge could not differ more. While Frege is a wholehearted rationalist, Kitcher's view of the nature of mathematical truth is more or less that of an empiricist. Frege's lifelong project was to prove that arithmetical truths are logical truths. Though we know that this project was not successful, most of his writings must be read in the light of the ambitious aim to find a solid foundation for arithmetic. For Frege psychology is a threat to this project. He polemically complains about "the corrupting incursion of psychology into logic" (Frege 1964: xiv). Kitcher on the other hand, thinks that all our knowledge is embedded within a psychological framework which holds that there are causes for believing something - a 
priori knowledge is not supposed to be an exception to this. Kitcher's psychological account of knowledge takes socio-historical changes in the field of logic and mathematics very seriously, and undermines the traditional picture of an ever-increasing amount of a priori knowledge. The traditional concept of a priori knowledge turns out to be a myth - a philosopher's fetish.

Surprisingly, Kitcher does not agree with this contrast. In his early paper, 'Frege's Epistemology' he ascribes to Frege a psychologistic account of knowledge, which he thinks is consistent with Frege's anti-psychologism. I shall argue that this interpretation is flawed and that Kitcher is reading too much of his own conception into Frege's epistemology. In the first section of this paper, Kitcher's definition of a priori knowledge will be outlined. In sections two and three, I shall discuss his attempt to harmonize Frege's notion of proof as a mental activity with his anti-psychologism. I shall argue that Kitcher's analysis undermines Frege's doctrine to keep apart reasons to believe and causes of belief. On a close reading one can find in Frege a clear-cut distinction which is expressed in his use of language; some textual evidence will be given in section four. In the last section I shall take up Frege's idea, that a priori knowledge and understanding are intertwined. From a naturalistic perspective it is hard to explain a priori knowledge, hence many naturalists explain it away. Quine, for instance, rejects the idea of a priori knowledge because for something to be known a priori it must be analytically true; and since there are no analytical truths, there is no a priori. Kitcher vindicates the possibility of a priori knowledge for naturalistic epistemology. He sharpens the Kantian definition of a priori knowledge as independent of one's experience. Roughly, knowledge is a priori if and only if it is produced by a process that would have produced knowledge no matter what particular experiences one might have had. Technically, Kitcher's explication has two parts, the first of which defines a priori knowledge in terms of warrants, the second serves as a definition for a priori warrants: 
(1) X knows a priori that $p$ if and only if X knows that $p$ and X's belief that $p$ was produced by a process which is an a priori warrant for it.

(2) $\alpha$ is an a priori warrant for X's belief that $p$ if and only if $\alpha$ is a process such that for any sequence of experiences sufficiently rich for $\mathrm{X}$ for $p$,

(a) some process of the same type could produce in X a belief that $p$ some process of the same type could produce in $\mathrm{X}$ a belief that $p$

(b) if a process of the same type were to produce in $\mathrm{X}$ a belief that $p$, then it would warrant $\mathrm{X}$ in believing that $p$

(c) if a process of the same type were to produce in $\mathrm{X}$ a belief that $p$, then $p .^{1}$

Proposition (1) derives from Kitcher's general psychological account of knowledge: "X knows that $p$ if and only if $\mathrm{X}$ believes that $p$ and X's belief that $p$ was produced by a process which is a warrant for it" (Kitcher 1983: 17). If knowledge is defined in terms of warrants, then a forteriori a priori knowledge is to be defined in terms of a priori warrants. In both cases, warrants are processes which produce beliefs and warrant the beliefs they produce; e.g. sense perception, mathematical intuition, encyclopedias, along with TV shows and gossipy neighbors.

Proposition (2) defines a priori warrants as independent of experience. Kitcher is very careful about the independence claim, since a priori knowledge may include concepts that presuppose experience. If I have never seen a triangle in my whole life, I cannot even understand basic geometric truths about triangles. To allow for the minimal role of experience in a priori knowledge, Kitcher introduces the notion of sufficiently rich experience. That an experience is sufficiently rich for me to know that $p$ means that I have all the concepts needed to entertain $p$.

Unfortunately, the independence claim cannot be met by the mere addition of the counterfactual conditional, that $\mathrm{X}$ would have

${ }^{1}$ See Kitcher (1980: 9f; 1983: 24; and 2000: 67); with slight modifications. 
known that $p$ even if X's experience were different. The difference between a priori and a posteriori knowledge would collapse, as the conditions for a priori knowledge would be satisfied already by $\mathrm{X}$ 's empirical knowledge of $p$. It is obviously wrong to say that $\mathrm{X}$ knows a priori that $p$, just because $\mathrm{X}$ keeps repeating the words of his teacher. To rule out the possibility of unexpected a priori knowledge, Kitcher states a direct connection between a priori warrants and a priori knowledge: If $\mathrm{X}$ knows a priori that $p$, then $\mathrm{X}$ does so, or could have done so, because of an a priori warrant, given any sufficiently rich experience. A priori knowledge is generated by a priori warrants, and an a priori warrant is a process that generates beliefs independently of experience. Thus in order to produce knowledge independent of experience, a process has (a) to be available independently of experience; (b) it must produce warranted belief independently of experience; and (c) it must produce true belief independently of experience; i.e., the warrant has to be ultra-reliable. ${ }^{2}$

Whereas many commentators concentrate on the second part of Kitcher's definition, I shall focus on the first part. The thesis "that the distinction between knowledge and true belief depends on the characteristics of the process which generates the belief" (Kitcher 1980: 7) is key to Kitcher's reliabilistic framework. Its application to a priori knowledge enables tradition-dependency as well as socio-historical backgrounds of mathematics and logics, to be brought in, as Kitcher famously shows. Nevertheless, I shall question the underlying assumption that the reasons to believe something a priori can be identified with the processes generating this belief.

${ }^{2}$ In recent discussions Kitcher considers a weak conception based on condition (a) and a strong conception of the a priori based on all three conditions (Kitcher 2000), but I shall not investigate this issue here. 


\section{Kitcher on Frege's epistemology}

The very title of Kitcher's paper, Frege's Epistemology, presupposes that Frege deals with epistemological issues. The importance of this observation cannot be stressed too much, since for a long time Frege was predominantly seen as a philosopher of language and mathematics. Kitcher and others succeeded in changing this paradigm, interpreting Frege's work from an epistemological point of view. I shall argue that although Kitcher is right to emphasize Frege's epistemological motives for logicism, he is exaggerating this view by imputing a kind of psychologism Frege does not endorse.

Frege's lifelong project was to find a secure and solid foundation for mathematical knowledge, and he was convinced that logical laws would provide such a foundation. By reducing arithmetical laws to logical laws he hoped to establish the epistemological status of arithmetical knowledge, showing, ultimately, how it flows from pure logic. At the heart of Frege's logicism lies the conviction that mathematical knowledge, in contrast to perceptual knowledge or knowledge by intuition, is immune from error. But, if this is the case, are we not entitled to ask, how logical laws are known? How does it come about that what is known on the basis of logical laws is superior to other knowledge? Paradoxically, Frege does not address this kind of question. The situation is even worse: Frege is not just silent about the nature of mathematical knowledge, his anti-psychologism seems to block epistemological discourse within the rigorous science of logic and mathematics. At this point Kitcher faces a genuine puzzle: If Frege's motives for logicism are primarily epistemological, why does he evade epistemological questions?

Kitcher reckons that the answer for Frege's silence lies in his faith in Kant: "Frege believed that the basic epistemological issues had already been settled [by Kant]" (Kitcher 1979: 241). Frege agrees with Kant's theory of knowledge, except for the nature of arithmetical knowledge. While Kant thinks that mathematical intuition is involved in geometry as well as in arithmetic, Frege denies this for arithmetical truths, as they are analytic. Because of his 
trust in Kant's theory of knowledge, Frege is reluctant to tackle the epistemological issues of his logicism. However, Kitcher finds systematic evidence for the close connection between Frege and Kant in their notion of proof. He claims that Frege and Kant share a traditional and non-formal concept of proof; i.e., proofs are not idealized sequences of symbols, but are "distinguished by the kind of knowledge they produce" (Kitcher 1979: 242). According to the traditional conception a proof is a "psychological activity which occurs in the minds of mathematicians. When we prove a proposition we engage in a special type of activity which generates a distinctive type of knowledge" (Kitcher 1979: 242). On the basis of this observation, Kitcher continues to ascribe to both Frege and Kant what he calls a psychologistic account of knowledge:

"On the psychologistic account, we suppose that the question of whether a person's true belief counts as knowledge depends on whether or not the presence of that true belief can be explained in an appropriate fashion. The difference between an item of knowledge and mere true belief turns on the factors which produced the belief (thus the issue revolves around the way in which a particular mental state was generated)." (Kitcher 1979: 243)

Whether a person can be said to know something, according to the psychologistic account, depends on the characteristics of the process in her mind. Since proofs are the produce of a highly reliable mental process they generate knowledge. It goes without saying that if Frege has a psychologistic account, it will fit Kitcher's reliabilism very well.

One objection intrudes immediately: How can Frege endorse a psychologistic account of knowledge, when he misses almost no opportunity to attack psychological explanations in the field of logic? Kitcher is well aware of this objection, and he offers a two-step strategy to refute it: firstly, he quotes various passages where Frege explicitly claims that proving is a psychological activity. Secondly, he tries to clarify the nature of Frege's antipsychologism by pointing out that Frege merely opposes the kind 
of psychologism which takes the contents of mathematical judgments to be mental entities. From this he concludes that Frege's anti-psychologism is compatible with the psychologistic account of knowledge (Kitcher 1979: 246). I shall discuss both steps in detail, but my critique concerns the second step, since Kitcher's analysis of Frege's anti-psychological doctrines is incomplete.

\section{Anti-psychologism}

Frege's attacks on psychology are various and it is sometimes difficult to separate polemical remark from argument. The fact that he never objects to the idea that judgments are mental processes, seems to support Kitcher's attribution of the traditional concept of proof. ${ }^{3}$ Against the formalist conception of inference, Frege claims that an inference does not belong to the "realm of signs" but is the "pronouncement of a judgment" (Frege 1984: 318). The expression "judgment" is clearly disambiguated here; it refers to the act of judging, not to the result of such an act. In a letter to Husserl, Frege admits that it is not counter to the purpose of the Begriffsschrift "if it occasions entirely new mental processes" (Frege 1980: 67). Probably the most explicit statement about inference as a psychological activity can be found in a letter to Jourdain, who asks, whether Frege regards judgment $(\vdash)$ as merely psychological. Frege answers that judging is an inner mental process, but that nonetheless something, if true, is objective and independent of the recognizer (Frege 1980: 78). Although Kitcher does not refer to it, this passage supports his interpretation extremely well: all inferences are judgments, to judge is a psychological activity, therefore inference is a psychological activity too. Yet, it does not enable the conclusion that an inference is nothing but the performance of a psychological act.

The second step in Kitcher's attempt to combine Frege's anti-

${ }^{3}$ Note that Frege's key epistemological concept is not belief or knowledge but judgment. Logical inferences are kinds of judgments; i.e. judgments made on the basis of other judgments. 
psychologism with the psychologistic account of knowledge is problematic. He summarizes Frege's doctrines as follows:

(a) logic does not record our actual thought processes

(b) truth is not what humans agree on

(c) the meaning of an expression is not an idea

(d) numbers are not mental entities ${ }^{4}$

On the basis of this list, Kitcher concludes that Frege's antipsychologistic doctrines do not rule out the psychologistic account of knowledge:

"One can believe that the difference between knowledge and true belief is to be found in the nature of the factors which produced the belief in the knower, one can regard inference as a mental process to which the laws of logic prescribe, and one can view proofs as codifications of ideal inferential processes, processes which produce certain knowledge, without committing oneself to any of the complex doctrines which Frege, correctly, spurned." (Kitcher 1979: 248; my italics)

Elsewhere Kitcher is very explicit about these factors being causal factors. He supposes that Frege would accept the following assumption: "With respect to any item of knowledge there must be a tree-like structure which represents the causal process through which the belief in question is produced" (Kitcher 1986: 302). If Kitcher is right, then Frege's derivations in the Begriffsschrift and in the Grundgesetze are designed to represent causal chains for believing the truth of mathematical formulas.

But Frege explicitly denies that our reasons for knowing something can be traced back to what causes our beliefs: "Although each judgement we make is causally conditioned, it is nevertheless not the case that all these causes are grounds that afford a justification" (Frege 1979: 2). Frege agrees that every judgment has its causes, but contrary to Kitcher, he does not derive the

$\overline{4}$ See Kitcher (1979: 248). 
conclusion that causal processes may also serve as a proof. He seems to think that causes belong to the realm of psychology and merely tell a generic story about the judgments they produce: "Clearly such an account of how men have come to hold something to be true is no proof" (Frege 1979: 3). Frege denies that psychology can contribute anything to the foundation of arithmetic, because this would "let us take the origin of an idea [...] or an account of the mental act and physical conditions on which we become conscious of a proposition for a proof of it" (Frege 1960: vi). With any psychologistic account to logic "we lose the distinction between the grounds that justify a conviction and the causes that actually produce it" (Frege 1979: 147). These remarks suggest another doctrine of Frege's:

(e) never confuse the reasons to believe something with its causes

If we amend the list of anti-psychologistic doctrines by adding (e), we can no longer attribute to Frege a psychologistic account of knowledge, because it conflicts with the claim that knowledge is a matter of the factors producing the belief in the knower. Kitcher seems to think that we can grant that the objects of judgments are not ideas [Vorstellungen] and still attribute to Frege the view that judgments are nothing but psychological acts. But Frege's anti-psychologism denies both the psychological understanding of the content of a judgment as well as the purely psychological understanding of the act of judging. Though he would agree with Kitcher that causal processes are going on when we draw conclusions from premises, he thinks that we commit a genetic fallacy when we take the causes to justify the conclusion.

\section{Judgment and holding to be true}

In this section the tension between Frege's anti-psychologism and his concession to the psychological reality of judgments shall be resolved. On close inspection of Frege's writings one can find a clear-cut distinction between justificatory and genetic aspects of 
judgments, that mirrors his use of language. For the sake of disambiguation Frege deliberately uses the verb "holding/taking to be true" [fürwahrhalten], when the causes of a judgment are at issue; whereas his use of "judgment" or "judging" alludes to the justificatory aspects of a judgment:

"Error and superstition have causes just as much as correct cognition. Whether what you take for true is false or true, your so taking it comes about in accordance with psychological laws. A derivation from these laws, and an explanation of a mental process that ends in taking something to be true, can never take the place of proving what is taken to be true." (Frege 1918: 58f.)

Here, the verb "taking for true" clearly has a psychological connotation - it serves as a vehicle for alleged judgments; i.e., judgments that lack justification. Error and superstition, as well as judgments, have causes, but in contrast to judgments a false belief has no justificatory aspects. Note that Frege never uses the expression "false judgment" for he seems to be convinced that judgments expressing false thoughts are "logically useless" (Frege 1980: 79). Hence, I can hold to be true what is objectively false, but this is different with judgment. Judgments may have causes too, but they do not give rise to judgments, for they can "never take the place of a proof".

Frege seems to suggest that judgments have psychological and justificatory aspects. Judgments are psychological acts in the sense that they are mental acts that people perform: "Both grasping a thought and making a judgment are acts of a knowing subject, and are to be assigned to psychology" (Frege 1979: 253). However, this is not exhaustive, because the causal history of a judgment does not reveal the grounds by which one judges. Hence, with regards to its justification a judgment is a logical act, or a "logically primitive activity [logische Urtätigkeit]" (Frege 1979: 15).

The idea of covering the psychological aspect of judgments with the notion of "taking to be true", goes back to Kant: "Taking something to be true [Fürwahrhalten] is an occurrence in our understanding that may rest on objective grounds, but that also 
requires subjective causes in the mind of him who judges" (Kant 1998: A820/B848). Thus, whether or not Frege and Kant share a traditional conception of proof, as Kitcher claims, they both respect the distinction between reasons and causes to believe. A judgment as a mental act is a holding-to-be-true, but regardless of its psychological reality it is still a judgment, which is in need of justification. One will find the term "holding to be true" in other contexts as well, nonetheless, Frege's use of language is deliberate. He applies the phrase of holding to be true when the grounds for justification are doubtful or missing, as in cases of error and conflicting beliefs (Frege 1892: 32; 1918: 69). The same holds for his rejection of psychologistic logic, which he thinks tries to reduce the laws of being true to "laws of holding as true [Gesetze des Fürwahrhaltens]" (Frege, 1964: xv-xvii).

\section{$5 \quad$ Frege's concept of a priori}

So far we have dealt with Frege's general conception of knowledge, not with his conception of a priori knowledge specifically. In this section I shall take up Kitcher's complaint that Frege does not address the question of how the foundation of logicism are to be known. On closer inspection, Frege gives some hints about how he thinks axioms and rules of inference are known. This final section does not present an argument for an alternative characterization of a priori knowledge, rather it suggests, along Frege's line of thinking, that any account of a priori knowledge should allow for the concept of understanding.

For Frege the distinction between a priori and a posteriori does not apply to the content of a judgment but to its justification: "Now these distinctions between a priori and a posteriori, synthetic and analytic, concern, as I see it, not the content of the judgement but the justification for making the judgement" (Frege 1960: $\S 3$ ). It is not what is judged or known is a priori, but the way a judgment is justified that is a priori or a posteriori. Though Frege does not discriminate further, the same holds for the analytic/synthetic distinction. Subsequent to his definition of 
natural numbers in the Grundlagen, Frege summarizes his conclusion: "I hope I may claim in the present work to have made it probable that the laws of arithmetic are analytic judgements and consequently a priori" (Frege 1960: $\S 87$ ). Hence, Frege seems to think that analyticity implies apriority: If $p$ is analytically true, then the judgment that $p$ can be justified a priori.

In Frege's technical writings the notions of apriority and analyticity almost disappear, instead the notion of self-evidence comes into focus. For Frege the truth of a thought is self-evident, if and only if nothing but its understanding is required for acknowledgment (Frege 1960: $\S 90$ ). However, when Frege introduces his very first axiom in the Begriffsschrift, he seems to feel forced to give a justification for its truth:

" $\vdash a \rightarrow(b \rightarrow a)$ says 'The case in which $a$ is denied, $b$ is affirmed, and $a$ is affirmed is excluded'. This is evident, since a cannot at the same time be denied and affirmed. We can also express the judgment in words thus, 'If a proposition $a$ holds, then it also holds in case an arbitrary proposition $b$ holds.' (Frege 1879: $\S 14$; my italics)" 5

But axioms are self-evident and not in need of a justification. This follows from Frege's own characterization: "The axioms are truths [...], but they are truths for which no proof can be given in our system, and for which no proof is needed" (Frege 1979: 205). So why does Frege feel forced to give a justification for it in the quoted passage?

Burge (1998: 317) suggests the sentence be read as emphasizing not an expression of our reasons, but as an elucidation of our understanding of Frege's first axiom. This calls attention to an interesting feature of a priori knowledge: the distinction between understanding an axiom and the recognition of its truth collapses, for we cannot understand an axiom without accepting its truth. In Fregean terms this means that the grasping of an axiomatic thought implies the judgment that the thought is true.

${ }^{5}$ We can find similar remarks in the Grundgesetze $\S 12$ and in $\S 6$ of the Begriffsschrift when Frege explains modus ponens. 
This observation gives rise to an alternative characterization of a priori knowledge, which includes human understanding rather than a priori warrants: the collapsing of understanding and judgment serves as a condition for a priori knowledge. A definition of a priori knowledge should not merely consist of conditions for what qualifies as a priori knowledge, but should say something about what it means to know a priori. The collapse of the distinction between understanding and judgment is an interesting feature, which any account of a priori knowledge has to consider.

A definition of a priori knowledge along these lines does not exclude socio-historical changes in the field of mathematics and logic. The background for our understanding may change. If we accept Kitcher's invitation and look back at the history of mathematical knowledge, we have to understand the relevant concepts used by the key historical figures, as they themselves understood them. Moreover, a definition of a priori knowledge in terms of understanding would give an explanation as to why mathematical statements can be puzzling. If you look at Frege's first axiom with the eyes of a young logic student, you may be puzzled by the thought that if a proposition is true, it is implied by any other proposition. Because of such puzzlement, this axiom represents one of the 'paradoxes' of material implication. Or, to give a less familiar example, one may be puzzled by the thought that for any two propositions one is either necessary or sufficient for the other. Yet, as soon as we understand the concept of a truth-functional conditional, the fog lifts. These examples show how understanding may take some time, but when we understand a proposition that can be known a priori, we no longer hesitate to accept its truth. Thus, an alternative characterization of a priori knowledge which takes the notion of understanding seriously, allows for a minimal role for experience, as well. 


\section{References}

Burge, T.: Frege on Knowing the Foundation. In: Mind, 107, p. 305-347, 1998.

Frege, G.: The Foundations of Arithmetic. Austin, J.L. (ed., trans.), New York: Harper and Brothers, 1960.

- The Basic Law of Arithmetic. Montgomery Furth (ed., trans.), Berkeley: University of California Press, 1964.

- Begriffsschrift, 1879. In: Heijenoort, J. (ed.), From Frege to Gödel, Cambridge: Harvard University Press, 1967.

- Posthumous Writings. Hermes, H. et. al. (ed.), Oxford: Basil Blackwell, 1979.

- Philosophical and Mathematical Correspondence. Brian McGuinness et.al., Oxford: Basil Blackwell, 1980.

- Collected Papers on Mathematics, Logic, and Philosophy. Brian McGuinness et.al., Oxford: Basil Blackwell, 1984.

— On Sinn and Bedeutung, 1892. In: Beaney, M. (ed.), The Frege Reader, Oxford: Blackwell, 1997.

- Thought, 1918. In: Beaney, M. (ed.), The Frege Reader, Oxford: Blackwell, 1997.

Kant, I.: Critique of Pure Reason. Guyer, P., Wood, A.W. (eds), Cambridge: Cambridge University Press, 1998.

Kitcher, P.: Frege's Epistemology. In: The Philosophical Review, 88, p. 235-262, 1979.

- A Priori Knowledge. In: Philosophical Review, 89, p. 3-23, 1980.

- The Nature of Mathematical Knowledge. Oxford: Oxford University Press, 1983.

- Frege, Dedekind, and the Philosophy of Mathematics. In: Haaparanta, L./ Hintikka, J. (eds), Frege Synthesized, Dordrecht: Reidel, 1986.

- A Priori Knowledge Revisited. In: Boghossian, P./ Peacocke, C. (eds), New Essays on the A Priori, p. 65-92, Oxford: Clarendon Press, 2000. 
Philosophisches Seminar

Universität Zürich

Zürichbergstrasse 43

8044 Zürich, Schweiz

pfisterer@philos.uzh.ch 